\title{
HISTÓRIA DA CIÊNCIA: BREVE HISTÓRICO DO ELETROMAGNETISMO E SUA RELAÇÃO COM A EPISTEMOLOGIA DE KARL POPPER
}

\author{
Fernando Temporini Frederico ${ }^{1}$, Neide Maria Michellan Kiouranis ${ }^{2}$, Dulcinéia Ester Pagani \\ Gianoto $^{2}$ \\ ${ }^{1}$ Mestrado em Educação para a Ciência e a Matemática. ${ }^{2}$ Docente do Programa de Pós-graduação em Educação para \\ Ciência e a Matemática - Mestrado e Doutorado - UEM. E-mail: fer.fred@bol.com.br
}

\section{RESUMO}

Este trabalho mostra os resultados de uma pesquisa realizada durante a disciplina de Epistemologia, Educação e Ciência do Programa de Pós-graduação em Educação para a Ciência e a Matemáticar, em que se buscou abordar parte da História da Ciência, no que se refere a descoberta do eletromagnetismo e, também, abordar algumas passagens históricas que marcaram o desvendar do magnetismo e dos experimentos do cientista Michael Faraday em busca da indução eletromagnética, relacionando tais descobertas com a epistemologia de Karl Popper. Os resultados mostraram que assim como argumentado por Popper, a ciência avança, em muitos casos, por meio de tentativas e erros, como ocorreu com a teoria eletromagnética.

Palavras-chave: História da Ciência; eletromagnetismo; falsificacionismo; filosofia da Ciência; Ensino de Ciências.

\section{INTRODUÇÃO}

Muito da comodidade e do conforto que boa parte da população tem hoje, como, por exemplo, andar de carro, assistir TV, ouvir rádio, acessar a internet, desfrutar dos benefícios das máquinas e aparelhos elétricos e, até mesmo, de trens de maglev que flutuam sobre trilhos, representam uma pequena parte do grande conjunto de conhecimentos relacionados à tecnologia que utilizam o eletromagnetismo como elemento fundamental para seu funcionamento. É claro, entender o magnetismo, a eletricidade e, consequentemente, o eletromagnetismo, não foi um processo simples e, sim, algo que levou tempo, demandou muito estudo, pesquisa e dedicação de grandes estudiosos que doaram parte de sua vida a entender e desvendar fenômenos.

Tales de Mileto, Hanz Christian Oersted, Michael Faraday são alguns, de muitos, que tornaram o mundo atual, uma realidade. Mas, como isso ocorreu? Como podemos relacionar o falsificacionismo de Popper com a história do eletromagnetismo?

Este trabalho, portanto, tem como objetivo fazer um breve resgate histórico desta imensa façanha que na descoberta do eletromagnetismo que permitiu ao homem um mundo tão moderno e, consequentemente, acentuar parte da epistemologia de Popper na busca pelo conhecimento. 


\section{METODOLOGIA}

Esta pesquisa se configura como qualitativa e que, de acordo com Mazzoti e Gewandsznajder (1998), apresentam, como uma de suas características marcantes, a utilização de hipóteses orientadoras. Neste caso, considera-se a hipótese de que o Falsificacionismo do filósofo austríaco Karl Raimund Popper (1902-1994) poderá ser evidenciado em alguns momentos relacionados com a história do eletromagnetismo, mais especificamente em torno das descobertas de Michael Faraday.

Para isso, foi realizada uma análise de alguns textos e bibliografias que narram registros históricos, que marcaram a história do eletromagnetismo, abordando desde o primeiro contato do homem com o magnetismo, eletricidade e, posteriormente, com o eletromagnetismo.

Paralelamente a isso, buscou-se relacionar a epistemologia proposta por Popper e possíveis relações com a história do eletromagnetismo.

\section{BREVE HISTÓRICO}

Os primeiros "encontros" do homem com ímãs já ocorriam em torno de três mil anos atrás. Os gregos foram os primeiros a observar fenômenos ligados ao magnetismo. De acordo com Guimarães (2011), os primeiros registros de que se tem conhecimento sobre as propriedades do magnetismo são atribuídos ao filósofo grego Tales de Mileto (século VI a. C.) que acreditava que uma espécie de ímã - o mineral magnetita - tinha uma alma. Já na China, por volta do século III a. C., a pedra da magnésia era conhecida como Tzu shih que significa "a pedra amante".

Passados alguns séculos e o contato de várias civilizações com o magnetismo, é por volta do século XI que os conhecimentos sobre essas forças passam a funcionar como componente utilizado na orientação marítima que permitiu que vários exploradores pudessem explorar mares e novas terras. Rival (2009) argumenta que a invenção da bússola foi um elemento crucial para o desenvolvimento da navegação na idade média e na época das grandes descobertas.

Em 1269, o francês Petrus Peregrinus talhou uma esfera de magnetita e a polvilhou com limalha de ferro, observando que elas se distribuíam em linhas, que por sua vez, se conectavam em dois pontos na esfera, o que ele denominou de pólos (GUIMARÃES, 2011).

Já em 1600, Willian Gilbert, cientista inglês, acreditava que todos os planetas, inclusive a Terra era um gigantesco ímã, com um imenso campo magnético que se estendia entre dois polos. Desde então, todos os pólos de todos os ímãs foram identificados como tendo um pólo norte e outro sul. 
De acordo com Guimarães (2011), Gilbert foi um experimentalista que dedicou seus estudos a fenômenos elétricos e magnéticos. Foi ele quem criou a palavra "elétrico", de elektron, âmbar" em grego. Seu livro mais importante foi De Magnete (obra dividida em 6 livros que reuniu conhecimentos sobre ímãs) que representa uma grande revolução no marco da ciência ocorrida nos séculos XVI e XVII. No livro II, são descritos fenômenos elétricos, sendo, portanto, o primeiro tratado publicado que aborda eletricidade.

De acordo com Rival (2009), as mudanças anunciadas por De Magnete de Gilbert juntaram-se a outras influências constituindo uma verdadeira revolução científica, associada a nomes como René Descartes, Francis Bacon e Galileu Galilei.

Já em 1729, o britânico Stephen Gray desvenda os princípios da condução e da isolação elétrica. Quatro anos depois, Charles Du Fay reconhece dois tipos de eletricidade, que em 1747 são qualificadas pelo americano Benjamim Franklin como positiva e negativa. Depois de alguns anos e de outras descobertas, Isola e Martins (2011) salientam que é em 1785 que o francês Charles de Augustin de Coulomb, utilizando uma balança de torção, conseguiu quantificar a força elétrica, propondo, então, a famosa Lei de Coulomb que afirma que as forças elétricas tem intensidade proporcional às cargas e inversamente proporcional ao quadrado da distância, proporcionando um grande marco que alavancou os estudos sobre eletricidade do qualitativo para o quantitativo e também, a invenção da bateria elétrica pelo físico italiano Alessandro Volta.

\section{ALGUMAS CONSIDERAÇÕES ACERCA DO ELETOMAGNETISMO}

A invenção de Volta criou os meios para a geração de correntes elétricas estáveis, o que abriu um novo mundo de possibilidades experimentais com a eletricidade, que veio a ser explorado nos anos subseqüentes, especialmente no trabalho de Oersted, Ampére e Faraday (GUIMARÃES, 2011, p. 120).

Em 1820, o físico dinamarquês Hans Christian Oersted percebeu que uma corrente elétrica poderia movimentar a agulha de uma bússola que estivesse próxima, ficando orientada perpendicularmente ao fio que portava a corrente, surge o Eletromagnetismo. Em 1822, André Marie Ampere (1775-1836) percebeu que uma bobina de um fio na qual percorria uma corrente elétrica tinha um comportamento semelhante a um ímã.

É, então, que entra em cena o inglês Michael Faraday (1791-1867). De origem humilde, o jovem Faraday trabalhava como encadernador de livros, aproveitando de seu ofício para ler tudo que podia. Sedento por saber, a eletricidade o fascinava. Dentre as constatações, Faraday 
descobriu uma maneira de gerar eletricidade através do movimento (CARVALHO, 2007). É em torno de seus experimentos em busca de conhecimento que buscaremos algumas relações com a Epistemologia de Karl Popper.

\section{ASPECTOS DA EPISTEMOLOGIA DE KARL POPPER}

Karl Raimund Popper (1902-1994) é um dos grandes nomes da epistemologia da ciência do século XX. O filósofo austríaco é conhecido por ter sido um dos grandes opositores ao indutivismo. Popper questionava se apenas a experiência e a observação eram suficientes para "derivar" um conhecimento, digamos confiável. Neste sentido, Peter e Mors (2009) salientam que Popper mostrou com argumentos lógicos que a indução poderia ser falha, ou seja, poderia não provar nada. Para o filósofo a ciência está sempre buscando a "verdade" embora não haja critérios, por meio dos quais se possa demonstrar que uma dada teoria seja verdadeira, na perspectiva de que a mesma seja capaz de resolver todos os problemas. Assim, uma atitude crítica pressupõe a "verdade absoluta ou objetiva como ideia reguladora; quer isto dizer, como padrão de que podemos ficar abaixo (POPPER, 1987, p. 59).

De acordo com Chalmers (1993, p. 44) "a ciência, pode-se ver que, contrariamente à reivindicação do indutivista, algum tipo de teoria deve preceder todas as proposições de observação e elas são tão sujeitas a falhas quanto às teorias que pressupõem".

Para Popper não há verdade absoluta, ele usa o termo - verossimilhança - na medida em que uma determinada teoria se aproxima da verdade. Sendo assim, de acordo com o epistemólogo, o conhecimento poderia progredir na medida em que fossem levantadas certas conjecturas (hipóteses) e, as mesmas, deveriam ser testadas pelos mais variados testes, incansavelmente. As que fracassassem deveriam ser abandonadas e substituídas por outras, sendo assim, a ciência progrediria por conjecturas e refutações, o que veio a ser chamado de Falsificacionismo. Segundo Popper (1982) se uma teoria deve ter conteúdo informativo, ela deve correr o risco de ser falsificada. Deste modo, toda vez que uma conjectura passasse nos testes, ela corroboraria com tal hipótese/conhecimento e, embora não haja verdade absoluta, ela seria capaz de explicar mais sobre o mundo e o universo, sendo melhor do que as anteriores.

Popper utilizava certo critério de demarcação entre o que ele considerava ou não ciência. Para ele, ciência era aquilo passível de ser verificado. Pode-se dizer, resumidamente, que o critério que define o status de científico de uma teoria é sua capacidade de ser refutada ou testada (POPPER, 1982. p. 66). 
Considerando a epistemologia de Popper, passamos agora a apresentar as possíveis relações dela com os experimentos de Michael Faraday.

\section{RESULTADOS}

O quadro abaixo traz um resumo de algumas experiências de Faraday.

Quadro I. Resumo de Experimentos

\begin{tabular}{|c|}
\hline Demonstração de Hans Christian Oersted (1777-1851) \\
\hline $\begin{array}{l}\text { Oersted demonstrou que havendo corrente elétrica em um fio, surge ao seu redor uma } \\
\text { propriedade do espaço capaz de defletir a agulha de uma bússola, competindo com o } \\
\text { magnetismo na Terra. }\end{array}$ \\
\hline Conjectura Levantada Por Faraday (Momento Empirista) \\
\hline $\begin{array}{l}\text { Supondo que, se uma corrente elétrica é capaz de criar efeitos magnéticos (como proposto por } \\
\text { Oersted), então, o inverso poderia ser verificado. Ao colocar bússolas em torno de um fio, } \\
\text { Faraday começou a perceber certo padrão (circular). Naquela época, a maioria dos cientistas } \\
\text { acreditava que as forças se deslocavam em linha reta, entretanto, Faraday tinha outra hipótese, } \\
\text { ele acreditava que havia uma força invisível que fluía em torno de um fio elétrico. Ele imaginava } \\
\text { também, que havia linhas circulares em torno de ímãs e que as mesmas poderiam ser capturadas } \\
\text { em seu trajeto. } \\
\text { Levantadas essas hipóteses, ele realizou alguns experimentos para tentar confirmar suas } \\
\text { conjecturas. }\end{array}$ \\
\hline Testes Experimentais (Momento Positivista) \\
\hline $\begin{array}{l}\text { De acordo com Guimarães (2011, p. 139), as anotações do diário de Michael Faraday mostram } \\
\text { que ele inicia em } 29 \text { de agosto de } 1831 \text {, alguns experimentos para tentar comprovar sua hipótese. } \\
\text { 1) Enrolou duas bobinas de fio de cobre em torno de um cilindro de madeira, cada uma delas } \\
\text { medindo cerca de } 30 \text { metros. Isoladas eletricamente uma da outra, Faraday conectou uma } \\
\text { bateria em uma e na outra uma espécie de galvanômetro (instrumento que detectava } \\
\text { eletricidade) - nada foi detectado, apenas um pequena deflexão; } \\
\text { 2) Ele repetiu o mesmo experimento, mas, desta vez, com as duas bobinas enroladas no anel de } \\
\text { ferro - os resultados foram os mesmos do primeiro; } \\
\text { 3) Já em outubro do mesmo ano, Faraday fez um experimento bem parecido com inverso do } \\
\text { realizado por Oersted: Movendo um ímã para dentro e para fora de um cilindro oco, no qual tinha } \\
\text { sido enrolada uma bobina, ele obtinha uma corrente elétrica circulando através da bobina, onde } \\
\text { ele verificou que, variando o campo magnético que permeia o circuito fechado, surgia corrente } \\
\text { elétrica induzida. A corrente foi detectada pela deflexão da agulha magnética, que era produzida } \\
\text { todas as vezes que o ímã se movia em relação à bobina. Esse mesmo efeito poderia ser observado } \\
\text { quando se movia a bobina em relação ao magneto. }\end{array}$ \\
\hline Corroboração \\
\hline $\begin{array}{l}\text { r testes, e corroborou com o } \\
\text { eriores, como a proposta por } \\
\text { n prática por meio de testes, }\end{array}$ \\
\hline
\end{tabular}




\section{DISCUSSÕES}

Guimarães (2011) salienta que Faraday tinha provado que efeitos elétricos poderiam ser produzidos por ímãs, mas, isso seria possível somente se os campos magnéticos correspondentes variassem com o tempo, mostrando porque os experimentos estáticos não tinham produzido nenhum efeito que pudesse ser detectado naquele momento. isso nos permite argumentar que o próprio Faraday necessitou variar seus testes experimentais para poder chegar a uma resposta que lhe aproximasse de suas conjecturas iniciais, ou seja, ele percebeu que um campo elétrico era gerado apenas se houvesse variação do campo magnético. Suas hipóteses iniciais foram refutadas.

De acordo com Peter e Mors (2009), para Popper não importa como o cientista chega às leis, o que importa é que elas podem ser falseadas. Neste sentido, o pensamento e as expectativas de Faraday acerca daquilo que acreditava - que um campo magnético poderia gerar um campo elétrico - foi subsidiado por experimentos, ou seja, passíveis de falseamento, assim como também, a sua conclusão se encaixa no falsificacionismo, uma vez que pode ser falseada.

Faraday fez vários testes até que conseguiu provar sua hipótese, ou seja, por meio de tentativas e erros, conseguiu chegar a tal constatação. Massoni (2005) argumenta que o próprio Popper afirmava que a ciência é uma das poucas atividades humanas em que o erro é severamente criticado e posteriormente corrigido, por isso, o filósofo ainda complementa que "no campo da ciência, muitas vezes aprendemos com nossos erros."

Guimarães (2011) completa:

Ao longo de sua extensa carreira, a maioria dos experimentos de Faraday foi de caráter exploratório. Em contraste com a meta final de Ampére, o objetivo final de Faraday não era uma descrição matemática de fenômenos eletromagnéticos, em vez disso, o que ele fazia era tentar observar e investigar minuciosamente novos fenômenos, perguntando em cada situação como a natureza se comportaria sob condições experimentais dadas. (GUIMARÃES, 2011, p. 139)

A citação do autor deixa entrever que embora Faraday tenha realizado vários testes, principalmente, aqueles que buscavam o inverso, daquele feito por Oersted, ou seja, de que um campo magnético poderia gerar um campo elétrico, Faraday não tinha como finalidade principal fazer apenas a descrição matemática do fenômeno, mas sim, observar como certos fenômenos naturais se comportariam, dadas certas condições experimentais.

Massoni (2009, p.11) afirma que "parece-nos estar associada ao critério de refutação a idéia do erro (tentativa e erro), tese que também é defendida por outros filósofos, como Bachelard". Ela ainda acrescenta: 
Ainda quanto à questão do erro, Popper salienta que não quer sugerir que a ciência se desenvolve de uma teoria para outra (aprendemos a partir dos nossos erros), mas que deve ser entendida como o desenvolvimento de um problema para outro cada vez mais profundo, "a teoria científica - ou explicativa - é, de fato, uma tentativa de resolver um problema científico" (MASSONI, 2009, p.11-12).

Pode-se associar a isso, a pretensão de Faraday em provar o inverso descoberto por Oersted, ou seja, Oersted mostrou que uma corrente elétrica poderia gerar um campo magnético, já, Faraday mostrou que um campo magnético geraria uma corrente elétrica (sobre certas condições).

Já, Carvalho (2007) argumenta que:

O trabalho realizado por Faraday no final de 1831 complementou a descoberta do eletromagnetismo por Oersted, mostrando a existência de um fenômeno inverso (produção de efeitos elétricos pelo magnetismo) e fornecendo a base necessária para o desenvolvimento de uma nova área de pesquisas (CARVALHO, 2007, p. 131).

Neste sentido, vê-se que o problema se tornou mais profundo, ou seja, a teoria do eletromagnetismo ficou mais explicativa, pois, com os experimentos de Faraday essa teoria passaria a dizer "mais" sobre o mundo. Além disso, só o fato de que tais fenômenos ao serem testados por Faraday apresentavam um cunho experimental, ou seja, podiam ser testáveis, revela sua teoria como científica, considerando o critério de demarcação proposto por Popper. Sem falar que, as descobertas de Oersted, Faraday e de muitos outros fazem parte de um conjunto de conhecimentos que proporcionou o progresso científico e tecnológico que se tem hoje, o que nos proporciona tanto conforto.

Popper (1982, p.66) afirmava que "todo teste genuíno de uma teoria é uma tentativa de refutá-la", ou seja, "a possibilidade de testar uma teoria implica igual possibilidade de demonstrar que ela é falsa." Com as palavras do epistemólogo, percebe-se que para o falsificacionista o importante é que uma teoria pode ser refutada e, Faraday ao buscar provar suas conjecturas, outras subjacentes surgiam e, com elas a necessidade de novos testes. Verifica-se, portanto, que um dos aspectos interessantes é que o magnetismo pode exercer efeito de um objeto sobre o outro, sem haver um contato material e, as descobertas, testes, hipóteses e constatações ao longo da história marcaram a saudável busca de conhecimento realizada pelo homem. 


\section{CONSIDERAÇÕES FINAIS}

Levando em consideração as ideias apresentadas, percebe-se que a história que marcou a descoberta e a estruturação da teoria do eletromagnetismo, assim como de outras teorias de igual teor, progrediram por meio de tentativas e erros, característica da epistemologia de Popper.

Embora Popper tenha sido um dos críticos ao positivismo e, parte de sua epistemologia, em alguns momentos também assuma esse caráter (positivista), um dos elementos mais marcantes de sua teoria seria justamente a demarcação do que seria ou não científico.

Diante disso, Faraday, assim como outros grandes cientistas, em determinados momentos assumiram uma postura, que ao nosso ver, se assemelhou, segundo Popper, à forma com que a ciência progride, ou seja, de acordo com um racionalismo lógico em que conjecturas são levantadas acerca de fenômenos que ocorrem no universo e, por meio de testes e experimentos (positivistas), as mesmas (hipóteses) poderão ser refutadas, ou ainda, poderão parecer próximas da verdade, garantindo-lhe o status de verossímel, o que vem a acarretar na corroboração do conhecimento.

Como reflexão final cabe lembrar que o ensino de ciências reproduz ainda uma visão indutivista da ciência, portanto, o acesso à discussão epistemológica poderá contribuir para uma melhor compreensão da natureza da ciência, bem como das limitações do conhecimento científico.

\section{REFERÊNCIAS}

Carvalho, Cristiano. A história da indução eletromagnética contada em livros didáticos de física. 2007. 143 fls. Dissertação (Mestrado em Educação). Universidade Federal do Paraná. Curitiba, 2013.

Chalmers, Alan F. O que é ciência afinal? São Paulo: Editora Brasiliense, 1993.

Guimarães, Alberto passos. A pedra com alma: a fascinante história do magnetismo. Rio de Janeiro: Civilização Brasileira, 2011.

Isola, Vinícius; Martins, Roberto de Andrade. A História do eletromagnetismo. Instituto de Física: Unicamp, 2011. Acessado em 04 de junho de 2013. Disponível em: http://www.ifi.unicamp.br/ lunazzi/F530_F590_F690_F809_F895/F809/F809_sem1_2003/992558 ViniciusIsola-RMartins_F809_RF09_0.pdf

Massoni, Neusa Terezinha. Epistemologias do Século XX. Porto Alegre: UFRGS, Instituto de Física, 2005. 
Mazzotti, Alda Judith Alves; GEWANDSZNAJDER, Fernando. O método nas ciências naturais e sociais - pesquisa quantitativa e qualitativa. São Paulo: Pioneira, 1998.

Peter, Eduardo Alcides; Mors, Paulo Machado. Uma visão histórica da ciência com ênfase na física. Porto Alegre: UFRGS, Instituto de Física, 2009.

Popper, Karl Raimund. Conjecturas e Refutações. 2 ed. Brasília: Editora Universidade de Brasília, 1982.

Rival, Michel. As grandes invenções da humanidade. São Paulo: Larousse do Brasil, 2009. 